\title{
Characterisation of material property variation across an inertia friction welded CrMoV steel component using the inverse analysis of
} nanoindentation data

\author{
O. Iracheta, C. J. Bennett*, W. Sun \\ Gas Turbine and Transmissions Research Centre, Faculty of Engineering \\ University of Nottingham, Nottingham NG7 2RD, United Kingdom \\ * corresponding author: chris.bennett@nottingham.ac.uk
}

\begin{abstract}
Keywords: Inertia Friction Welding, Phase transformations, nanoindentation, FE modelling of depth-sensing indentation, inverse analysis.
\end{abstract}

\begin{abstract}
In this study, a new application of the inverse analysis of the depth-sensing indentation technique based on the optimization theory has been satisfactorily demonstrated. The novel approach for determining the mechanical properties from experimental nanoindentation curves has been applied in order to generate the elastic-plastic stress-strain curves of three phases located across the joint of a like-to-like inertia friction weld of a CrMoV steel, i.e. the parent phase of tempered martensite and two child phases formed during the IFW process, martensite in the quenched and over-tempered condition. The inverse analysis carried out in this study consists of an optimization algorithm implemented in MATLAB, which compares an experimental nanoindentation curve with a predicted indentation curve generated by a 3D
\end{abstract}


finite element model developed using the ABAQUS software; the optimization algorithm modifies the predicted curve by changing the material properties until the best fit to the experimental nanoindentation curve is found. The optimized parameters (mechanical properties) have been used to generate the stress-strain relationships in the elastic-plastic regime that can be used to simulate numerically the effects of the variation in material properties arising from phase transformations occurring across the joint during the IFW process of a CrMoV steel.

The proposed inverse analysis was capable of fitting experimental load-depth $(P-h)$ curves produced with a Nanoindentation Nanotest NTX unit from three characteristic regions located across the joint where the above mentioned phases are known to exist. The capability of the inverse analysis to build the stress-strain relationship in the elastic-plastic regime using the optimized mechanical properties of the parent metal has been validated using experimental data extracted from the compressive test of an axisymmetric sample of tempered martensite [1]. According to previous experimental studies, the presence of martensite in the quenched and over-tempered condition formed during the IFW of shaft sections of CrMoV steel are responsible of the 1.52:1 harder and 0.75:1 softer regions, compared to the region where the tempered martensite is located [2-4]. These ratios are in very good agreement with the optimized magnitudes of yield stress provided by the inverse analysis, that is, $1.54: 1$ for the quenched martensite and $0.68: 1$ for the over-tempered martensite, compared to the optimized value of yield stress of the tempered martensite. Moreover, a relative difference of less than $1.5 \%$ between the experimental and predicted maximum depth $\left(h_{\max }\right)$ supports the capability of the method for extracting the elastic-plastic mechanical properties defining each of the indented regions. 


\section{Introduction}

Inertia Friction Welding (IFW) is a solid-state joining technique employed in the manufacturing of multi-material components. The energy for welding is stored in a flywheel as kinetic energy and is dissipated as heat when one stationary workpiece and one rotary workpiece are brought into contact. Therefore coalescence is obtained through the combined effects of pressure and relative motion of the mating workpieces to cause heating through friction and consequently plastic deformation with the purpose of forming enough primary atomic-level bonds. [5].

As can be inferred from Figure 1, the thermo-mechanical history induced during the IFW process of SCMV steel results in a distribution in the material properties across the joint leading to an $\sim 1.52: 1$ harder region and an $\sim 0.75: 1$ softer region in relation to the base metal of tempered martensite, identified as TM (500HV0.1). The hard (750HV0.1) and soft (375HV0.1) zones are attributed to the formation of quenched martensite (QM) and overtempered martensite (OTM) [2, 3].

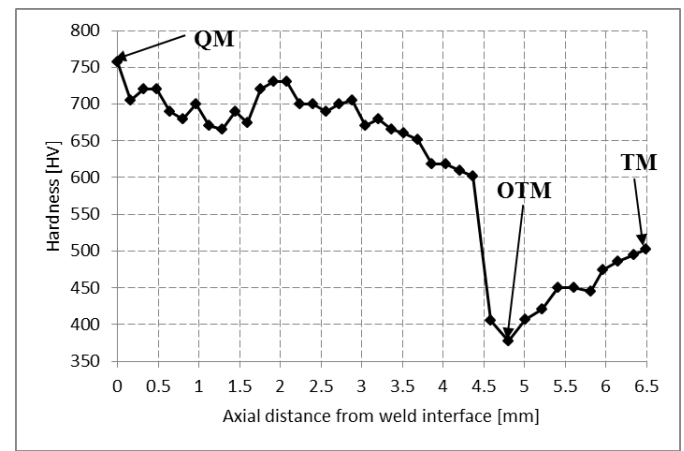

Figure 1. Microhardness profile across the HAZ of an SCMV steel weld trial [4]. 
Polymorphic transformations during IFW of SCMV result not only in variations in physical properties but are also accompanied by volumetric changes arising from atomic rearrangements in the crystal structure. At the onset of cooling, austenite formed during the welding stage transforms back to quenched martensite and therefore the microstructure experiences a positive (increase) volumetric change [6], which consequently results in a significant stress reduction in the vicinity of the weld line of the as-welded component [7].Further investigations on the evolution of residual stresses during the IFW of SCMV steel based on the finite element method [8] concluded that at the onset of transformation from austenite to martensite, the volumetric changes experienced in the lattice relax up to $70 \%$ of the tensile hoop stress found in the vicinity of the weld line near the inner surface and that the interaction of soft regions of austenite and hard regions of heat unaffected martensite accounts for up to $17 \%$ of the peak tensile stress. Additionally, it was found that the evolution of residual stresses is dominated by thermal strains during the initial cooling period and by phase transformation strains during the final cooling period. Given that the majority of the residual stresses are generated during the initial cooling period, the build-up of residual stresses was shown to be highly sensitive to the definition of elastic properties and therefore the need for a more accurate representation of elastic-plastic properties was suggested. The proposed technique in the present study is based on an inverse analysis of the depth-sensing indentation test. This test involves pressing a hard indenter into a softer body, the specimen, by applying either a controlled load or displacement. The instrument records the depth of penetration beneath the surface of the specimen as a function of load in a load control test, or contrariwise in a displacement control test, such that a load-depth $(P-h)$ curve is generated [9] as schematically illustrated in Figure 2. 


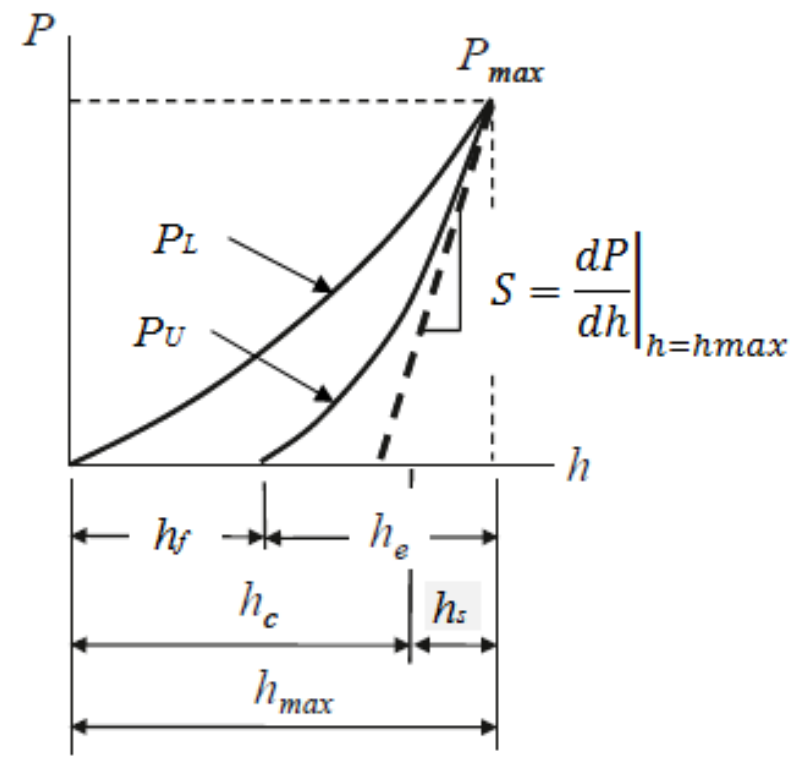

Figure 2. Typical $P$ - $h$ curve recorded during the depth-sensing indentation test [9].

The loading portion of the curve is typically described by Kick's Law, i.e.

$$
P_{L}=C h^{2}
$$

where $P_{L}$ is the loading force, $h$ is the indentation depth and $C$ is the loading curvature which is related to the geometry of the indenter tip and the material properties of the specimen. Upon unloading, only elastic displacements are recovered $\left(h_{e}\right.$ in Figure 2$)$ and therefore after the load is completely removed, the indenter has left an impression in the specimen of depth $h_{f}$, or final depth [10].

Based on Sneddon's work [11], Ternovskii et al. [12] derived Equation 2 to relate the contact stiffness to the elastic modulus,

$$
S=\frac{d P}{d h}=\frac{2}{\pi} E_{r} \sqrt{A}
$$


where $S$ is the contact stiffness, $A$ is the projected area of the elastic contact and $E_{r}$ is the reduced modulus obtained by Equation $3[13,14]$.

$$
\frac{1}{E_{r}}=\frac{\left(1-v^{2}\right)}{E}+\frac{\left(1-v_{i}^{2}\right)}{E_{i}}
$$

Here, $E$ and $v$ are the Young's modulus and Poisson's ratio for the specimen and $E_{i}$ and $v_{i}$ are the respective parameters for the indenter. Oliver and Pharr [10] represented the unloading curve $\left(P_{U}\right)$ by a power law relation of the form:

$$
P_{u}=D\left(h-h_{f}\right)^{m}
$$

where $D$ and $m$ are constants determined by a least square fitting procedure. The analytical differentiation of Equation 4, evaluated at maximum depth $\left(h_{\max }\right)$ results in an expression for the contact stiffness $(S)$

$$
S=\left.\frac{d P_{u}}{d h}\right|_{h=h_{\max }}=m D\left(h_{\max }-h_{f}\right)^{m-1}
$$

which can be used to find the elastic modulus through Equation 2. Recent trends towards a more accurate determination of elastic-plastic material properties have encouraged the development of numerical approaches, or inverse analysis techniques, to recover the elasticplastic material properties from $P$ - $h$ curves. Empirical analytical functions of the $P-h$ curves have been derived by fitting the results of extensive FE simulations of the indentation process in order to estimate hardness and elastic-plastic material properties (e.g. [15-18]). Cheng and Cheng $[19,20]$ adopted the dimensional analysis approach to derive relationships between hardness, loading and unloading curves, and mechanical properties of solids. Dao et al. [21] 
included the concept of representative strain of indentation in order to reduce the number of apparent unknown variables in the dimensionless functions derived by Cheng and Cheng. However, these methodologies rely on fitting procedures and are therefore valid only within the material properties space considered to build the functions. A variant of the inverse analysis technique employs the theory of optimization to find the set of material properties that minimizes the error between an experimental, or theoretical experimental, and a predicted $P$ - $h$ curve (e.g. $[22,23])$.

The present study, exploits the capabilities of the nanoindentation technique to measure small volumes of materials in order to characterize the distribution of mechanical properties developed during the IFW process of a like-to-like weld of $\mathrm{CrMoV}$ steel, arising from the phase transformation of the base material (tempered martensite) into two extra phases, i.e. quenched martensite and over-tempered martensite. An inverse analysis of the depth-sensing indentation tests at nano-scale, based on the optimization theory, has been applied to determine the constitutive relationship of each phase given the limitations of the analyses based on fitted data and the approximation errors of traditional empirical methods (e.g. Oliver-Pharr).

\section{Material and methodology}

\subsection{Sample preparation}

Super-Chromium-Molybdenum-Vanadium (SCMV) is a low alloy ferritic steel of the CrMoV family, which provides an enhanced ultimate strength to weight ratio and plain section fatigue strength, an improved hardenability and an equivalent or better notch fatigue strength, ductility and fracture toughness. This is achieved by the employment of a triple vacuum melt route (VIM/EFR/VAR) to increase the cleanness of the material and a two-stage heat- 
treatment, comprised by austenitization at $935^{\circ} \mathrm{C}$ for 30 minutes and oil quenching and lastly, tempering at $570^{\circ} \mathrm{C}$ for 300 minutes. Therefore, SCMV in the fully heat-treated condition exhibits tempered martensite as white nodular precipitates sitting on the lath packets [24]. A cross-weld section of an inertia friction weld trial of SCMV-to-SCMV was cut, ground and polished to $1 \mu \mathrm{m}$ before indentation. As shown in Figure 3, Quenched martensite (QM) and over-tempered martensite (OTM) extend between approximately 0-3 and 3-5 mm away from the weld line. Beyond $\sim 5 \mathrm{~mm}$ from the weld line, outside the heat affected zone, tempered martensite $(\mathrm{TM})$ remains unaffected.

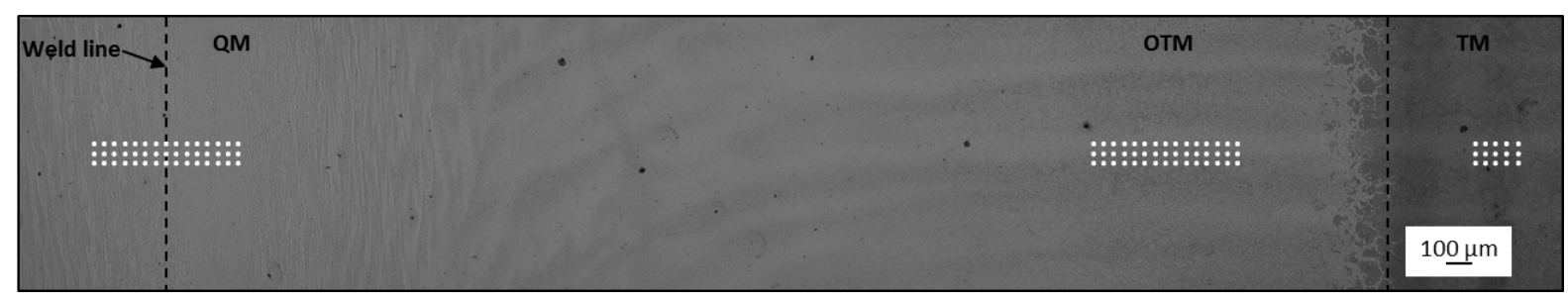

Figure 3. Joint section of an inertia friction welded SCMV-to-SCMV showing a schematic illustration of the indentation tests performed at three different regions (indenter impressions and indentation offsets are not to scale).

Experimental $P-h$ curves have been extracted with a Nanoindentation Nanotest NTX unit using a Berkovich indenter. The indenter has been loaded from an initial contact force $\left(P_{i}\right)$ of $0.1 \mathrm{mN}$ to a maximum force $\left(P_{\max }\right)$ of $200 \mathrm{mN}$ in a time interval of $20 \mathrm{~s}$, and subsequently unloaded to zero in the same time interval. As schematically illustrated in Figure 3, thirty indentations were performed in the vicinity of the weld line and in the region within the weld line and the base metal, where QM and OTM are known to exist, respectively, and fifteen indentations at locations removed from the heat affected zone, where the TM remains unaffected. The indentation unit has been setup to conduct three rows of indentations, with an offset of $50 \mu \mathrm{m}$, along the joint every $50 \mu \mathrm{m}$ up to a maximum of five and ten columns. The extracted data is dispersed with a standard deviation of 22.6, 44.0 and $26.8 \mu \mathrm{m}$ about the mean $h_{\max }$ for the QM, OTM and TM respectively. The Martens hardness (HM) was 
calculated from each experimental $P$ - $h$ curve and compared to the Vickers hardness (HV) reported in Figure 1. The curve with the minimum relative difference between HM and HV was selected as representative of the respective phase, as illustrated in Figure 4.

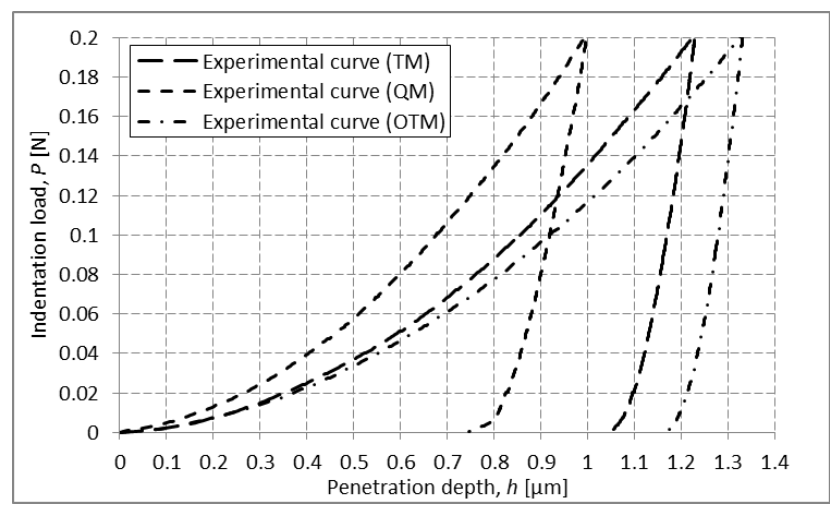

Figure 4. Experimental $P$ - $h$ curves corresponding to tempered martensite (TM), quenched martensite (QM) and over-tempered martensite (OTM) phase.

2.2 Inverse analysis of the depth-sensing indentation test

The inverse analysis presented in this study is based on an iterative optimization procedure implemented in MATLAB to find the set of material properties that generates the predicted $P$ - $h$ curve that best fits the corresponding experimental curve. The optimization model has been defined as follows:

$$
\begin{gathered}
f\left(x_{i}\right)=\sum_{j=1}^{N}\left[h_{j}{ }^{\text {exp }}-h\left(\boldsymbol{x}_{\boldsymbol{i}}\right)_{j}^{\text {pre }}\right]^{2} \rightarrow \min \\
\boldsymbol{x}_{\boldsymbol{i}}=\left[E, \sigma_{y}, n\right]^{T}, \quad i=1,2,3 \\
\boldsymbol{x}_{i}{ }^{L} \leq \boldsymbol{x}_{i} \leq \boldsymbol{x}_{i}{ }^{U}, \quad i=1,2,3
\end{gathered}
$$


where $f\left(x_{i}\right)$ represents the objective function to be minimized, $h_{j}^{\text {exp }}$ the depth of the experimental curve at a load step $P_{j}, h\left(\boldsymbol{x}_{i}\right)_{j}{ }^{\text {re }}$ the depth of the predicted curve at the same step of loading, $N$ is the total number of data points included in the loading-unloading curves and $\boldsymbol{x}_{\boldsymbol{i}}$ is a vector containing the optimization parameters (mechanical properties), or the optimization variables. In order to address the non-uniqueness issue of the inverse analysis of indentation purely based on experimentally and FE simulated $P$ - $h$ curves $[25,26]$, the space of possible solutions has been limited by a set of bound constraints, where $\boldsymbol{x}_{i}{ }^{L}$ and $\boldsymbol{x}_{i}{ }^{U}$ represent the lower and upper boundaries of $\boldsymbol{x}_{i}$ as detailed in section 3.1. Equation 6 has been coded in a MATLAB script using the lsqnonlin function available in the Optimization Toolbox. Therefore, $\boldsymbol{x}_{i}$ (the properties being optimized) is modified using a trust-regionreflective algorithm, starting from the initial guess vector $\left(x_{0}\right)$, in order to reduce the sum of the squared error in the prediction of indentation depth at each load increment point $(j)$, until convergence is reached as detailed in Figure 5. 


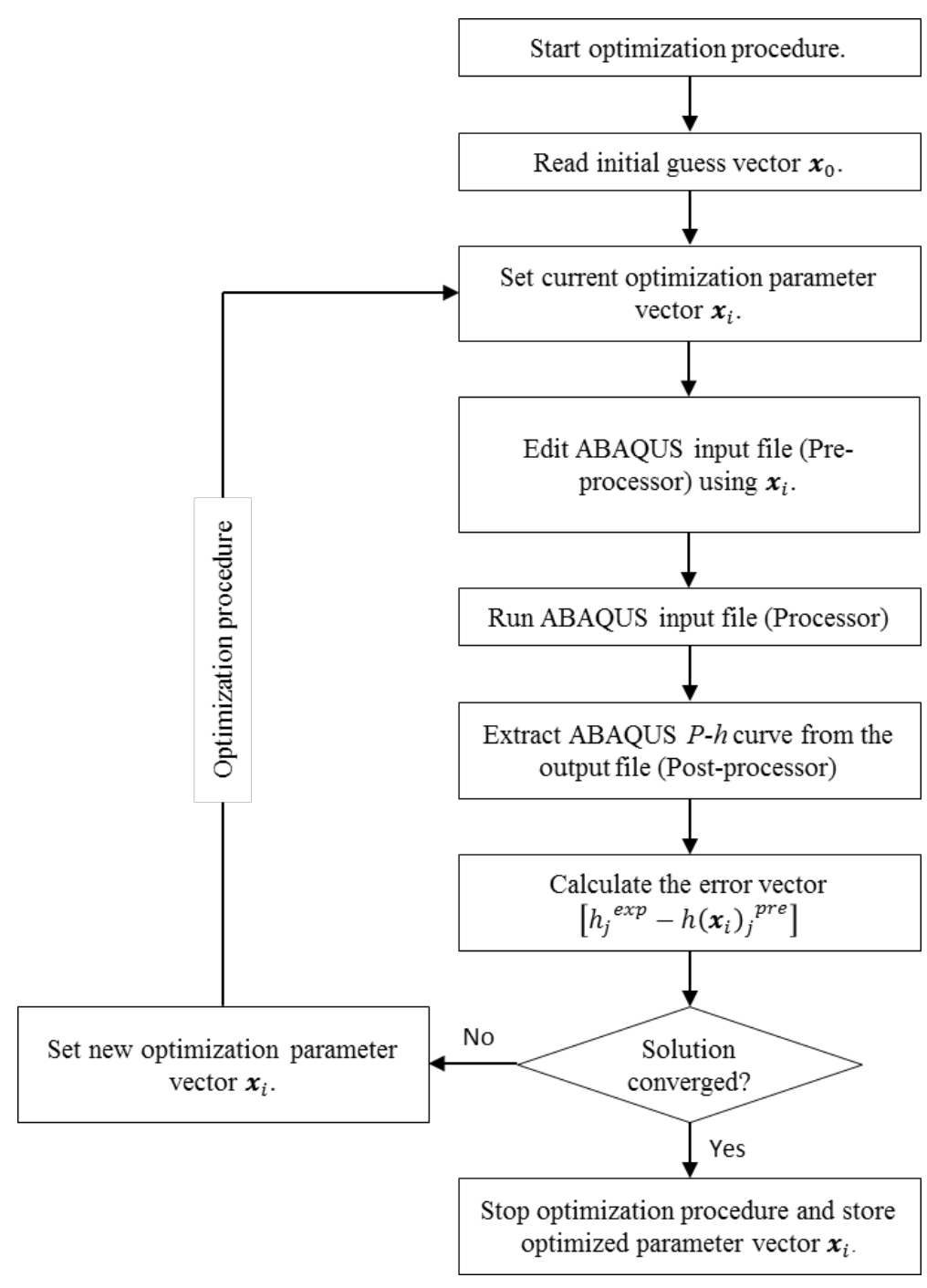

Figure 5. Flow chart of the optimization procedure.

\subsection{FE modelling of depth-sensing indentation}

The indentation test of a bulk metal, using a Berkovich indenter, has been numerically simulated in this study using the ABAQUS Standard 6.12-3 FE code. Due to symmetry, only one-half of the model has been analysed in a 3D space as illustrated in Error! Reference source not found. 

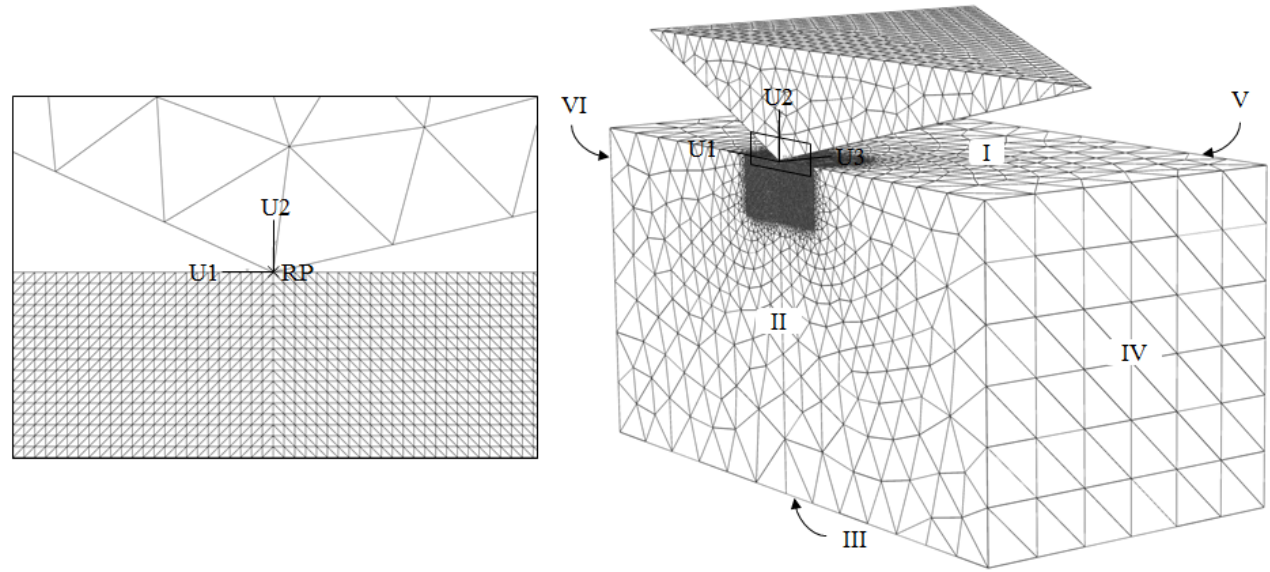

Figure 6. Geometry and boundary conditions defined in the 3D indentation model

The Berkovich indenter has been defined as a 3D discrete rigid body using 3-node 3D rigid triangular facet elements (R3D3 in ABAQUS). The specimen has been defined as a 3D deformable body assuming an isotropic elastic-plastic material model following a Swift power law hardening rule,

$$
\sigma=K\left(\varepsilon_{e}+\varepsilon_{p}\right)^{n}
$$

where $\sigma$ is the stress at the corresponding total strain $\varepsilon_{T}=\left(\varepsilon_{e}+\varepsilon_{p}\right), \varepsilon_{e}$ and $\varepsilon_{p}$ are the elastic and plastic strain components, $K$ represents the strength coefficient and $n$ the strain hardening exponent. From boundary conditions at $\varepsilon_{p}=0, K$ can be defined as follows:

$$
K=E^{n} \sigma_{y}^{1-n}
$$

where $E$ is the Young's modulus and $\sigma_{y}$ the yield stress. The geometry of the deformable body was discretized by 4-node linear tetragonal elements (C3D4 in ABAQUS). Beneath the indenter, where steep strain gradients are expected, a higher element density has been 
defined. In this zone, the ratio of height $(b)$ to length $(d)$ of the mesh was maintained to unity in order to avoid excessive distortion.

Boundary conditions in the deformable body (specimen) are defined as follows: nodes of plane I represent the surface of the specimen and therefore are allowed to displace in the three directions (U1, U2, U3) yet are not allowed to cross the plane of symmetry (plane II) in fulfilment with the compatibility equations. However, the displacement of nodes in the contact areas is governed by a master-slave surface-to-surface boundary condition. The master-slave contact interaction between the indenter (master) and the specimen surface (slave) was defined with zero contact friction since the effect of friction on the indentation process can be assumed negligible [16]. The contact pair has been defined using a surface-tosurface formulation that considers the shape of both the slave and master surfaces in the region of contact. The contact constraints are imposed according to a penalty method in which the contact pressure $(p)$ at a point in the deformable body is proportional to the penetration distance $(h)$ :

$$
\begin{gathered}
p=0 ;(h<0) \\
p=k_{p} h ;(h \geq 0)
\end{gathered}
$$

where $k_{p}$ is a large penalty stiffness coefficient used to minimize the penetration of the slave surface into the master surface at the constraint locations. By default, ABAQUS sets the penalty stiffness $\left(k_{p}\right)$ to 10 times a representative underlying element stiffness $\left(k_{e}\right)$. Therefore the surfaces separate if the contact pressure reduces to zero, and two separated surfaces come into contact when the contact pressure is greater than zero. The nodes of plane II, the plane of symmetry, can only deform in this plane $(\mathrm{U} 3=\mathrm{UR} 1=\mathrm{UR} 2=0)$. The displacements of the nodes 
at plane III located at the bottom surface of the deformable body are fully constrained $(\mathrm{U} 1=\mathrm{U} 2=\mathrm{U} 3=0)$ and nodes at the external planes $(\mathrm{IV}, \mathrm{V}$ and $\mathrm{VI})$ are traction free. $\mathrm{A}$ sufficiently large domain of size $30 \times 30 \times 60 \mu \mathrm{m}$ has been adopted to model a semi-infinite deformable body such that the solution results insensitive to the far-field effects. To validate this assumption, traction free nodes were constrained with roller boundary conditions such that displacements are only allowed in their own planes. The motion of the rigid body is determined by a reference point (RP) located at a node in the tip of the Berkovich indenter and therefore the loading and boundary conditions associated with the indenter have been assigned to this point. The RP, and therefore the indenter, is only allowed to translate in the vertical direction $(\mathrm{U} 1=\mathrm{U} 3=\mathrm{UR} 1=\mathrm{UR} 2=\mathrm{UR} 3=0)$. A force of one-half the indentation load in the vertical direction is defined at the RP. The analysis has been split into two static load control steps; during the loading step a load of $0.1 \mathrm{~N}$ is applied to the reference point in the rigid indenter, during the unloading step the load is reduced to $0.0 \mathrm{~N}$. In the initial step (defined for pre-processing) the RP of the indenter is constrained coincident to a node located in the centre of the specimen surface at the edge of the surface of symmetry to avoid losing contact between nodes in the specimen and the indenter during the loading step.

\subsection{Sensitivity of $h_{\max }$ to mesh size, load increments and element type}

This section describes the use of the FE model detailed previously to investigate the sensitivity of the predicted maximum indentation depth $\left(h_{\max }\right)$ to variations in model parameters, such as the mesh size and load step increments. Given the FE model has been defined as a load controlled analysis, $h_{\max }$ is an appropriate value to study the model parameters as it is related to the elastic and inelastic strain energy absorbed by the specimen during loading. The mesh sensitivity study carried out to establish the optimum mesh refinement at the contact zone beneath the indenter started with a coarse mesh of size ratio 
$\left(d / h_{\max }\right)$ close to unity, where $d$ is the length of the mesh and $h_{\max }$ is the maximum indentation depth obtained from experimental data; therefore the mesh sizes span from $\sim 1.2$ to $0.2 \mu \mathrm{m}$. As shown in Figure 7, $h_{\max }$ reaches convergence at a contact mesh size of $0.6 \mu m$ since the relative difference in $h_{\max }$ can be considered negligible $\left(\Delta h_{\max }<1.6 \%\right)$ compared with the value predicted by the finest mesh.

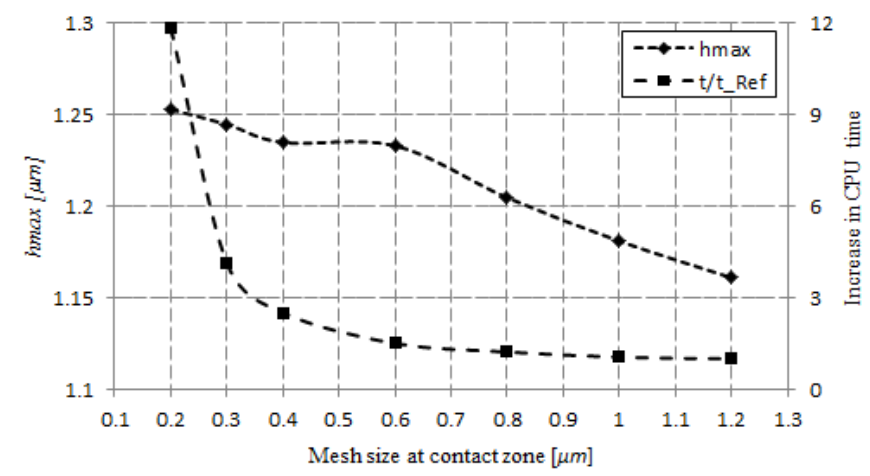

Figure 7. Sensitivity of $h_{\max }$ to the mesh size at the contact zone.

Finer mesh sizes $(0.3$ and $0.2 \mu \mathrm{m})$ are expected to provide more accurate results given the contact conditions between the indenter and the specimen are better represented during the simulation but also at an expected higher computation cost as illustrated in Figure 7. During loading, the nodes at the edges of the perfectly-sharp indenter come first into contact with the surface of the specimen and consequently the elements of the specimen are deformed until the surfaces of the indenter and the specimen generate an interface of contact governed by the shape of the indenter, in fulfilment with the surface-to-surface contact pair defined in the FE model. However, a contact condition may arise in which one node of the indenter exerts a load between two nodes of the deformable body, particularly in nodes along the edges of the indenter and more significantly at nodes at the edges approaching the perfectly sharp tip of the indenter. Therefore as the element density in the deformable body increases, the distance between nodes decreases and the accuracy of the model to follow the downward 
displacement of the indenter increases. The improved accuracy in representing the shape of the indenter gained by a finer mesh results in a better enforcement of contact constraints as the loading procedure continues and consequently a better prediction of the underlying element stiffness, which is of vital importance when using the penalty method. As can be seen, the difficulties in representing the contact conditions by coarser meshes are highlighted by fluctuations in the predictions of local stiffness $(P / d h)$, as illustrated in Figure 9, which consequently results in distorted loading curvatures. The general trend is an increase in stiffness as the load is increased, which is associated with the strain-hardening of the material. Figure 8 and Figure 9 include a coarse mesh of $1.2 \mu \mathrm{m}$ for a better appreciation of the effects of the mesh size on the shape of the loading curvature; the peaks in stiffness indicated with arrows in Figure 9 generate the distortions in the shape of the corresponding loading curvature indicated in Figure 8. These fluctuations are therefore attributable to the discrete nature of the numerical contact conditions.

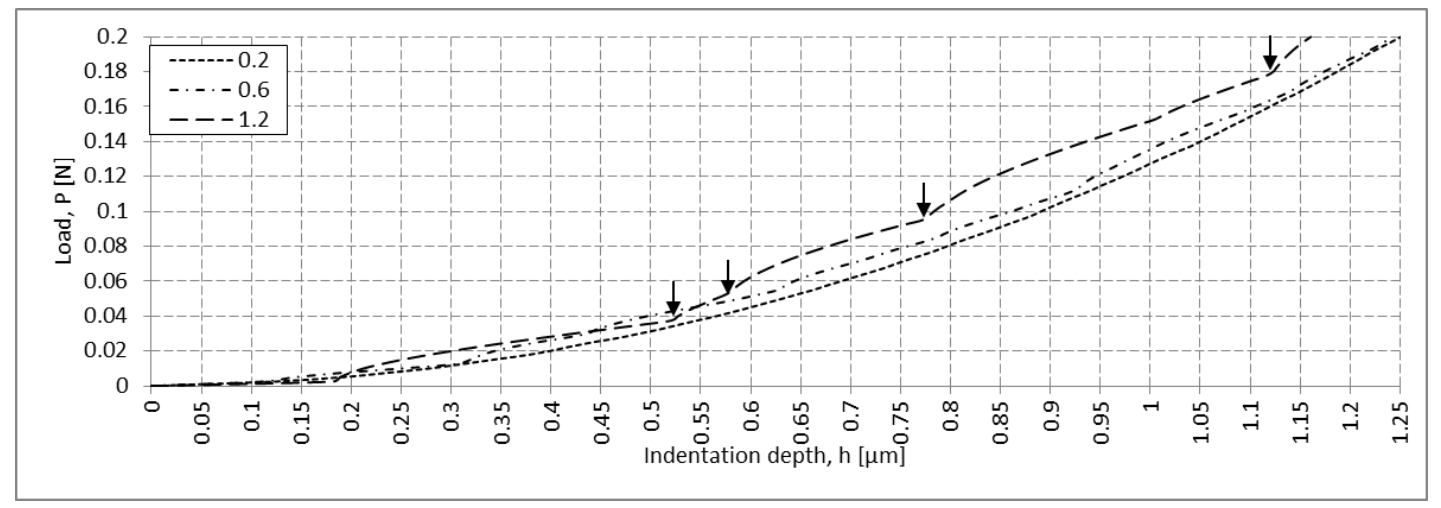

Figure 8. Effects of the mesh size on the shape of the loading curvature of indentation.

Therefore, although a higher computation time is expected, the reduced error induced to the optimization procedure by a smoother loading curve generated by a finer mesh of approximate size of $0.2 \mu \mathrm{m}$ makes it a more favourable option for this study. 


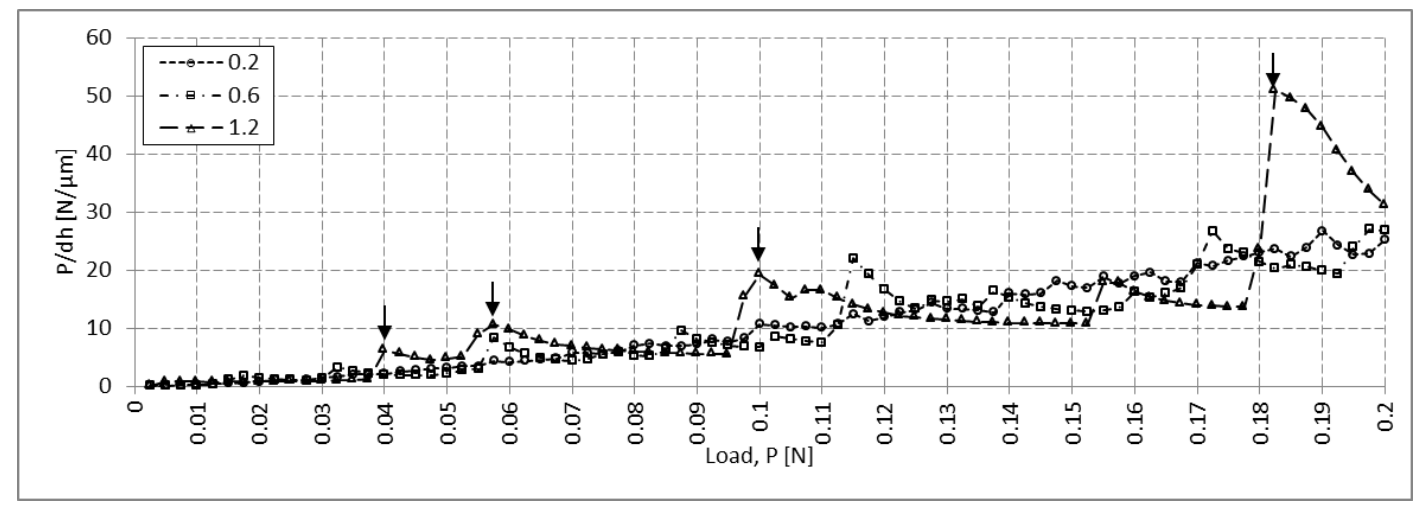

Figure 9. Local stiffness of the deformable body at a point beneath the tip of the indenter.

It is to be noted that in order to ensure equilibrium is satisfied in the solution of the FE model, an increase in mesh density requires an increase in the number of loading steps. Figure 10 provides evidence of the almost negligible sensitivity of $h_{\max }$ to the number of steps used in the solution process $\left(\Delta h_{\max }<0.073 \%\right)$, where $\Delta h_{\max }$ is the relative increment in $h_{\max }$ predicted by a model defined with 80 loading steps compared to a model of 200 steps. However, as expected the run times are significantly increased by increasing the number of load steps. Additionally, from the sensitivity study of $h_{\max }$ to yield stress described later in this section, it is possible to prove that a relative difference of $+0.073 \%$ in $h_{\max }$ represents a relative difference of less than $-0.25 \%$ in yield stress. Therefore, we can conclude 80 load increments provide a robust solution that ensures equilibrium is satisfied at every load increment when using a mesh at the contact zone of approximate size of $0.2 \mu \mathrm{m}$.

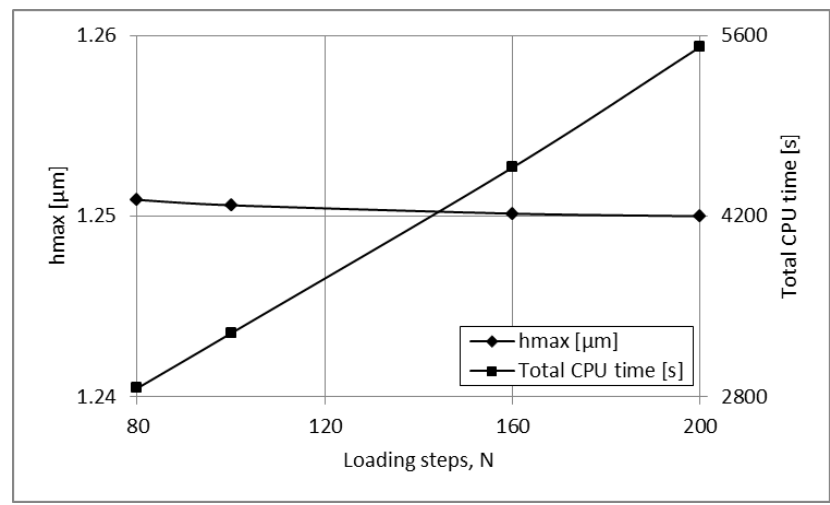


However, since the optimization procedure involves the iterative solution of a highly nonlinear problem with an added complexity of a constantly changing non-linear material property database, and considering the effects of the loading increments on the prediction of indentation depth is negligible, an automatic increment FE model with defined initial, minimum and maximum increment sizes will be used in this study with the intention of ensuring the robustness of the optimized solution. The change in $h_{\max }$ predicted by a model using an automatic step increment, relative to a model of 200 loading steps, is approximately $+0.35 \%$, which consequently induces a relative difference of less than $-1 \%$ to the yield stress prediction. Having discussed the advantages of a proper fit between the surface of the indenter and the elements of the deformable body on the accuracy to capture the indentation depth $h$, it is reasonable to investigate the necessity of using quadratic elements to mesh the deformable body. Three simulations modelled with quadratic elements of 1.2, 0.6 and $0.2 \mu \mathrm{m}$ of length were run and compared with the curve predicted by the model meshed with $0.2 \mu \mathrm{m}$ linear elements as illustrated in Figure 11. As expected, the sensitivity of $h_{\max }$ to the element mesh size is negligible when using quadratic elements as the distance between any 2 nodes, and the added capability of a quadratic variation of displacement is more able to represent the contact conditions. The change in $h_{\max }$ between the $0.2 \mu \mathrm{m}$ quadratic element model, relative to the $0.2 \mu \mathrm{m}$ linear element model, is less than $+1.43 \%$ which represents an approximate relative change of less than $-4.2 \%$ in the prediction of yield stress according to the parametric analysis carried out in this study. However, the computation time of the quadratic solution is drastically increased by a factor of 56 , which makes it computationally unaffordable for the optimization algorithm. Quadratic elements however, can be used to assess some of the factors affecting depth-sensing indentation data such as tip imperfections arising from the 
complexity of manufacturing indenters with ideal geometry and wear occurring in practice, and the pile-up/sink-in phenomena. A difference of $-0.9 \%$ in the FE prediction of $h_{\max }$ was observed with an indenter modelled as non-ideal, relative to the model assuming a perfectly sharp indenter. This in turn may induce a difference in the predicted value of $\sigma_{y}$ of up to $+2.7 \%$. In order to account for the non-ideal geometry, the tip of the indenter was assumed flat with a triangular area of approximately $0.0032 \mu \mathrm{m}^{2}$, which corresponds to the imperfection usually observed in experimental Berkovich indenters [27]. The degree of pileup/sink-in is one of the most serious factors that complicate the interpretation of indentation data as this cannot be directly related to the $P$ - $h$ curve. During the fully plastic regime, it is observed that elastic-plastic materials may either pile-up or sink-in depending on the strain hardening exponent $n$ and the ratio $\sigma_{y} / E$ [9]. Therefore, the study of the evolution of the surface profile during indentation provides additional information to limit the space of possible solutions of the inverse analysis of indentation. This feature however, will be included in the optimization algorithm of a further investigation.

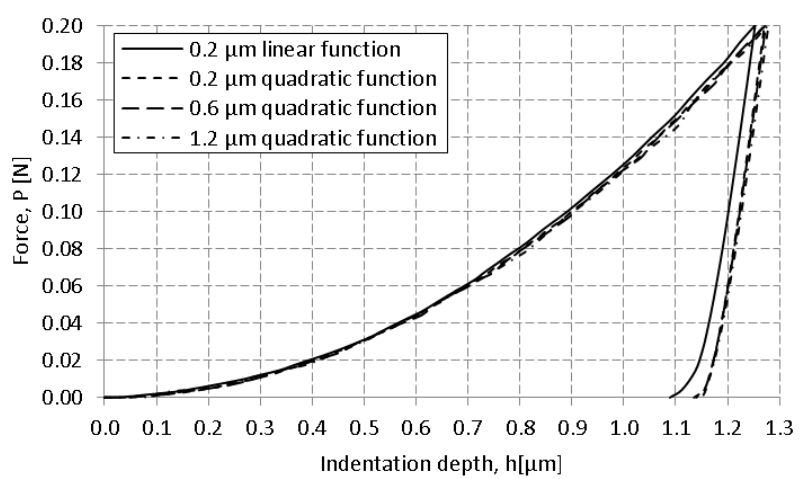

Figure 11. $P$ - $h$ curves predicted using second order elements. 
2.5 Sensitivity of loading and unloading steps in depth-sensing indentation predictions to material properties of the specimen

The sensitivity of the predicted $P-h$ curves, with respect to an FE simulation using a set of reference material properties, to the individual variation of up to $\pm 20 \%$ in the values of these properties is presented in Figure 12. The yield strength largely influences the indentation depths of the $P$ - $h$ curve as can be appreciated in Figure 12a due to the larger load $(P)$ required to produce yielding and consequently plastic flow, yet the shape of the unloading curve appears to remain unaltered. This is not the case for the variation of the Young's modulus, which slightly modifies the loading requirements and consequently the indentation depth, but also changes the unloading shape defined by the contact stiffness $(S)$ due to the known dependency of $S$ to the elastic modulus $E$ (see Equation 2), as shown in Figure $12 \mathrm{~b}$. Therefore, it is possible to conclude the loading portion of the curve is largely influenced by the yield strength whereas the unloading portion is more sensitive to the Young's modulus of the bulk metal.

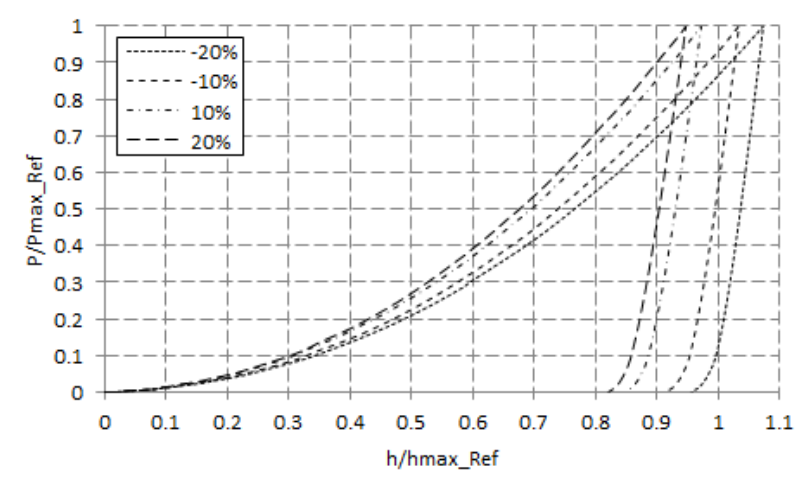

a)

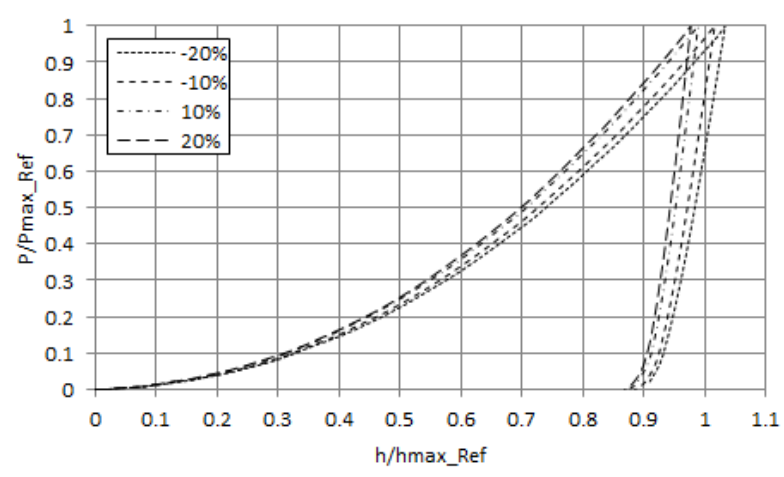

b)

Figure 12. Effects of the a) yield strength and b) elastic modulus on the predicted empirical parameters of loading and unloading. 
The sensitivity of the predicted indentation depth, $h$, at $P_{\max }$ is shown in Figure 13 to be almost negligible to the variation of the Poisson's ratio and the strain hardening exponent compared to $E$ and $\sigma_{y}$. Furthermore, unlike the strain hardening exponent, Poisson's ratio of metals has been studied extensively in the past and it is typically accepted to be around 0.3 in the elastic regime, increasing to 0.5 in the plastic regime [28]; therefore it is not included as an optimization parameter in this study but it is rather considered as a constant mechanical property of magnitude of 0.3 . Figure 13 also highlights the predicted value of $h_{\max }$ is affected by both the magnitude of $E$ and $\sigma_{y}$ in a ratio of $0.17: 1 \%$ and $0.34: 1 \%$ respectively. The nearly linear relationship between $\sigma_{y}$ and $h_{\max }$ has been used to test the sensitivity of the FE model to some simulation parameters as detailed previously.

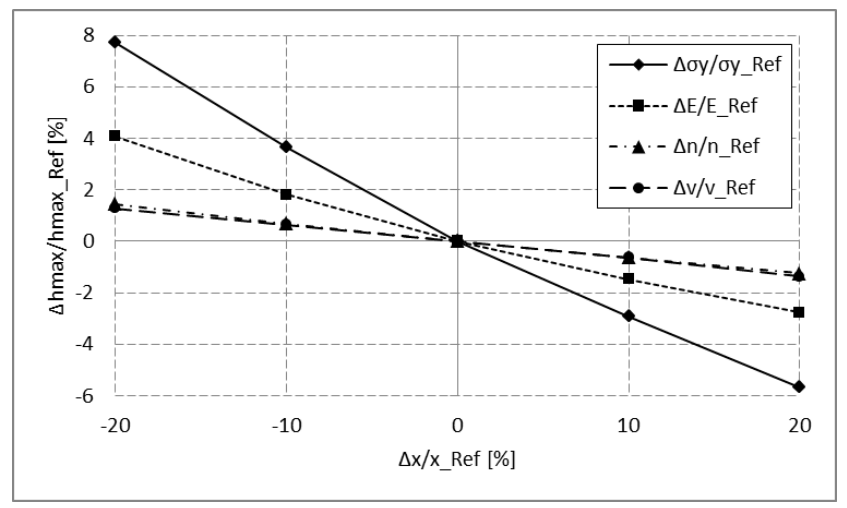

Figure 13. Effects of the variation of $\sigma_{y}, E, v$, and $n$ on the maximum indentation depth $\left(h_{\max }\right)$.

\section{Results and discussion}

Three different regions across the joint of an IFWed CrMoV steel have been characterised using the inverse analysis technique proposed in this study, including the parent phase of tempered martensite (TM) and two child phases formed as an effect of the welding process, over-tempered martensite (OTM) and quenched martensite (QM). 
3.1 Determining elastic-plastic properties across the heat affected zone from instrumented indentation data

The assessment of the capability of this method to determine the elastic-plastic properties of each of these phases choosing a set of initial guess material properties is summarized in Table 1. The bound constraints have been defined as follows: for most steels, Young's modulus has a value of about $200 \mathrm{GPa}$ [29] and therefore the solution is limited to a range between 200$225 \mathrm{GPa}$, although for the case of TM, the space was reduced to 200-215 GPa to improve the fitting. Following Tabor's relationship [30] of Vickers hardness (reported in Figure 1), the yield stress at $8 \%$ plastic strain of martensite in the tempered, quenched and over-aged condition formed during IFW of SCMV steel reaches approximately 1600, 2500 and 1200 $\mathrm{MPa}$, respectively and therefore the respective constraints for the initial yield stress $\left(\varepsilon_{p}=0\right)$ were set to $1300-1600,2000-2200$ and 900-1200. SCMV in the tempered condition tested in compression experiences low to moderate strain hardening [1] and therefore the $n$ value was limited to up to 0.15 for the TM phase and up to 0.25 for QM and OTM. The initial guess parameters were set to start at the respective upper bound constraints.

Table 1. Set up and results for optimization.

\begin{tabular}{|c|c|c|c|c|}
\hline Phase & $\begin{array}{c}\text { Optimization } \\
\text { parameter }\end{array}$ & $\begin{array}{l}\text { Initial guess } \\
\text { parameters }\end{array}$ & Bound constraints & $\begin{array}{l}\text { Optimized } \\
\text { parameters }\end{array}$ \\
\hline \multirow{3}{*}{$\begin{array}{c}\text { Tempered } \\
\text { martensite }(\mathrm{TM})\end{array}$} & $E$ & $215000[\mathrm{MPa}]$ & $200000<E[\mathrm{MPa}]<215000$ & $213954[\mathrm{MPa}]$ \\
\hline & $\sigma_{y}$ & $1600[\mathrm{MPa}]$ & $1300<\sigma_{y}[\mathrm{MPa}]<1600$ & $1409[\mathrm{MPa}]$ \\
\hline & $n$ & 0.15 & $0<n<0.15$ & 0.1015 \\
\hline \multirow{3}{*}{$\begin{array}{c}\text { Quenched } \\
\text { martensite }(\mathrm{QM})\end{array}$} & $E$ & $225000[\mathrm{MPa}]$ & $200000<E[\mathrm{MPa}]<225000$ & $205824[\mathrm{MPa}]$ \\
\hline & $\sigma_{y}$ & $2200[\mathrm{MPa}]$ & $2000<\sigma_{y}[\mathrm{MPa}]<2200$ & $2170[\mathrm{MPa}]$ \\
\hline & $n$ & 0.25 & $0<n<0.25$ & 0.25 \\
\hline
\end{tabular}




\begin{tabular}{|c|c|c|c|c|}
\hline Over-tempered & $E$ & $225000[\mathrm{MPa}]$ & $200000<E[\mathrm{MPa}]<225000$ & $220608[\mathrm{MPa}]$ \\
\hline martensite & $\sigma_{y}$ & $1200[\mathrm{MPa}]$ & $900<\sigma_{y}[\mathrm{MPa}]<1200$ & $952[\mathrm{MPa}]$ \\
\hline (OTM) & $n$ & 0.25 & $0<n<0.25$ & 0.0971 \\
\hline
\end{tabular}

The capability of the inverse analysis proposed in this study to fit three different experimental indentation $P-h$ curves extracted from the three characteristic regions formed across the joint of IFWed cylinders of $\mathrm{CrMoV}$ steel is evidenced in Figure 14. A relative error in the predicted maximum indentation depth $\left(h_{\max }\right)$ less than $1.44,1.13$ and $1.16 \%$ for the martensite in the tempered, quenched and over-tempered condition respectively has been achieved. Recalling from section 2.5 , the predicted value of $h_{\max }$ is affected by both the variation in the magnitude of $E$ and $\sigma_{y}$ in a ratio of $0.17: 1 \%$ and $0.34: 1 \%$ and therefore a slight variation along the indentation loop can be attributed partly to the unconstrained optimization algorithm implemented at this stage and partly to the complexity in representing by an FE model the contact mechanics involved in a depth-sensing indentation operation, including the deformation of the indenter, the effects of tip imperfections and misalignment of the indenter or the interaction of asperities at the indenter-sample interface.

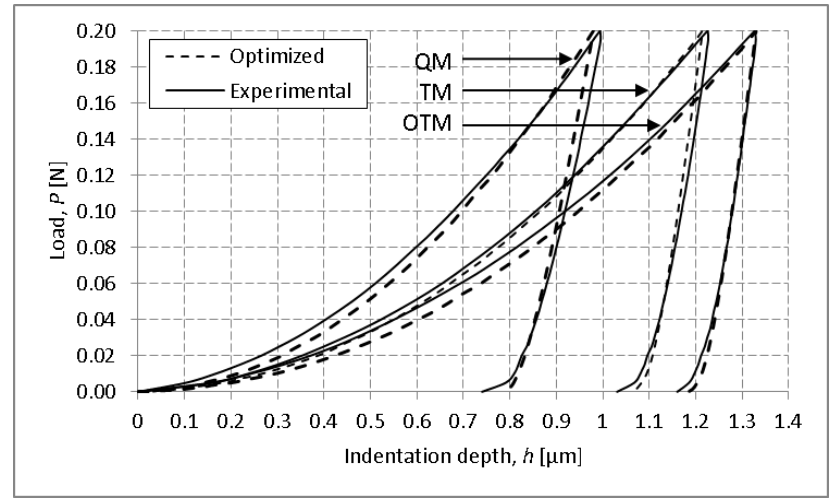

Figure 14. Comparison of $P$ - $h$ curves obtained from experimental data and FE model using the optimized parameters 
for martensite in the tempered (TM), quenched (QM) and over-

tempered (OTM) condition.

In order to prove the capability of the model to converge to an optimum solution, the effects of the initial guess parameters on the optimized parameters have been evaluated as presented in Figure 15. 

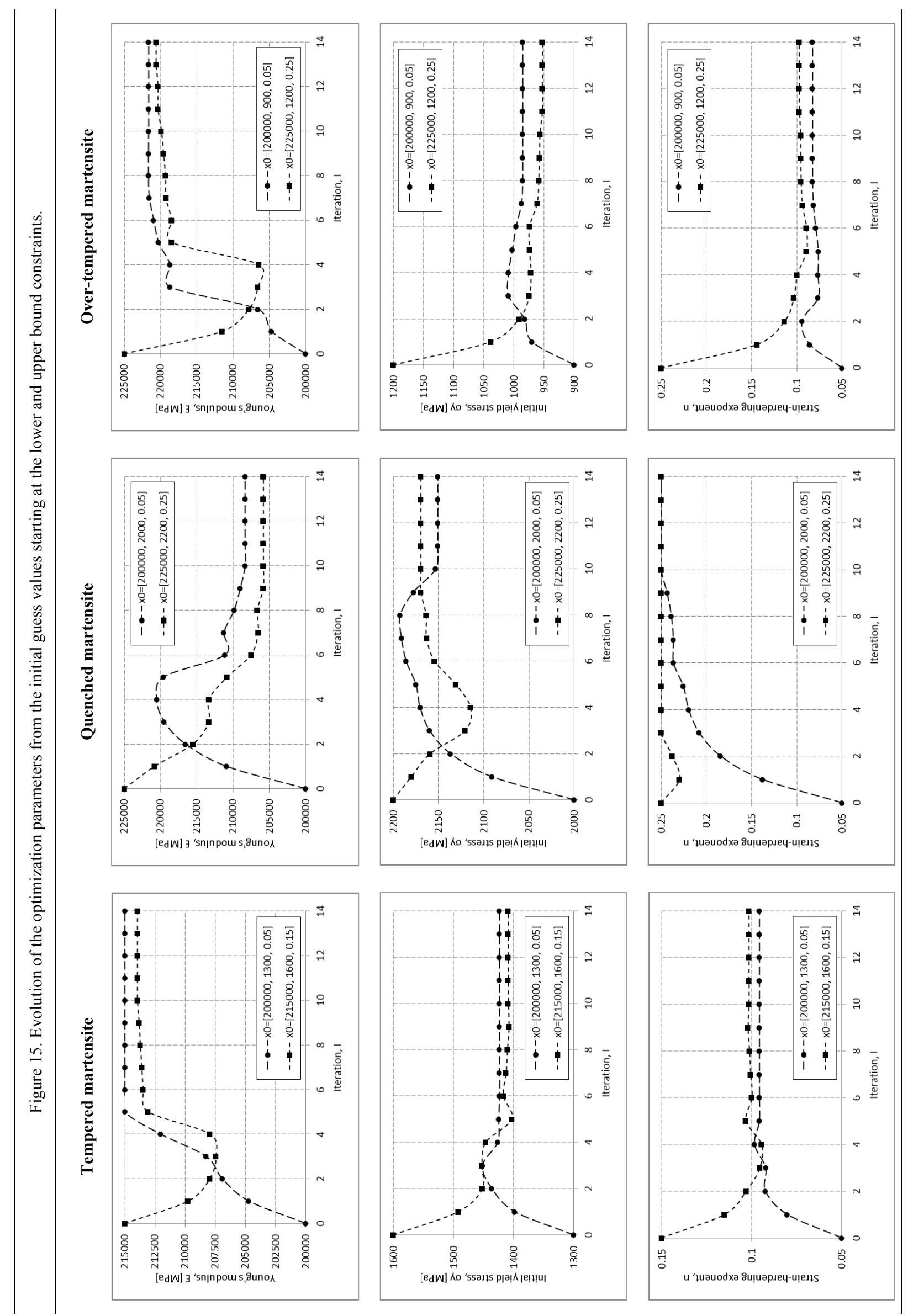
The initial guess parameters, $E, \sigma_{y}$ and $n$ respectively, were changed to start from the lower bound constraints, i.e. at 7, 19 and $67 \%, 11,9$ and $80 \%$, and 11,25 and $80 \%$ away from the original initial guess parameters for the case of TM, QM and OTM respectively. Notwithstanding, the optimization model converged to a solution to within a difference of $0.5,1.0$, and $5.7 \%, 1.2,0.9$ and $0.0 \%$, and $0.5,3.5$ and $15 \%$ for the case of TM, QM and OTM respectively, relative to the values approximated by the original model. Convergence of all optimized parameters has been achieved rapidly in less than 10 iterations for the three phases. A higher variation in the solution of the strain hardening exponent $(n)$ was expected given the complexity of representing analytically the plastic behaviour of metals and the limited information available in the $P-h$ curve regarding the strain hardening behaviour of the indented metal, as can be inferred from to the low sensitivity of the curve to this optimization parameter as shown in Figure 13. However, after convergence has been reached, the inverse analysis approach proposed in this study proved to be a highly reliable method for predicting the key material properties to generate a full elastic-plastic stress-strain curve of a strain hardening material as detailed below.

\subsection{Evaluation of the across-weld properties}

Figure 16 presents a comparison of two stress-strain curves, a curve obtained experimentally from a compressive test of an axisymmetric sample of $\mathrm{CrMoV}$ steel in the tempered condition at room temperature [1] and a curve built by evaluating Swift's relationship (Equation 7) with the optimized material properties predicted for the tempered martensite reported in Table 1. An almost negligible difference of less than 1 and $0.9 \%$ in the optimized value of Young's modulus and yield stress respectively is exhibited within the elastic region $\left(\varepsilon_{p}=0\right)$, relative to the experimental properties, regardless of the initial guess value. After $8 \%$ of plastic strain $\left(\varepsilon_{p}=0.08\right)$ the flow stress reaches a relative difference of approximately $10 \%$, which can be 
attributed to the volume of material tested by these two techniques. Furthermore, it is to be recognized that Swift's law is an idealization that usually does not represent the constitutive relationship of a real engineering material.

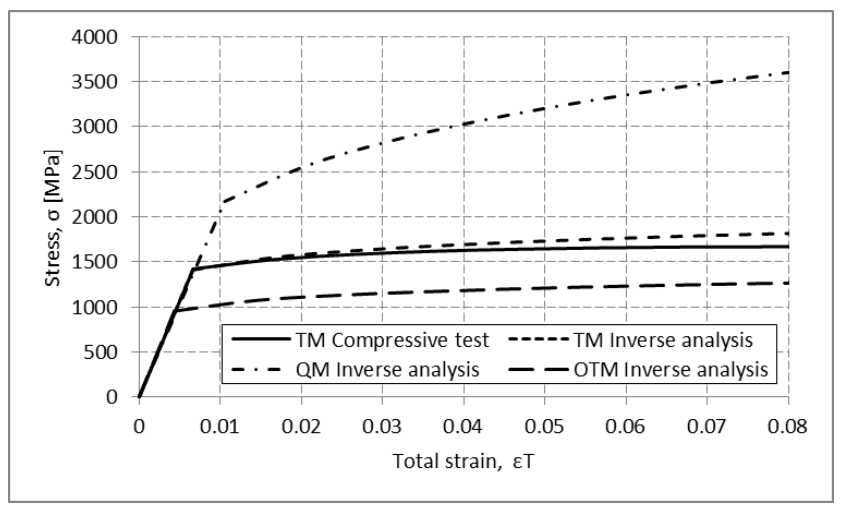

Figure 16. Comparison of the stress-strain curve generated experimentally from a compressive test on a CrMoV steel sample and the curve built using the optimized material properties predicted by the inverse analysis.

Tempered martensite exhibits equiaxed grains of $\alpha$-ferrite (bcc) plus spherodized precipitates of $\mathrm{Fe}_{3} \mathrm{C}$ (cementite) [31] and therefore different material properties are expected from grain to grain. The typical grain size of tempered martensite is about 2-3 $\mu \mathrm{m}$ and the projected area left by the Berkovich indenter penetrating the tempered martensite at full load under the conditions specified in section 2.1 is that of an equilateral triangle of base $a \sim 9.5 \mu \mathrm{m}$ and height $l \sim 8.2 \mu \mathrm{m}$ as schematically illustrated in Figure 17; therefore during nanoindentation, the indenter is in contact with a region shared by a small number of grains. On the other hand, the compressive test extracts the stress-strain relationship of the tempered martensite as a bulk metal comprised of several millions of grains and therefore a slight difference in the stress-strain curve is expected. Additionally, considering the IFW process is largely 
dominated by thermal strains, this difference is not expected to influence the prediction of the residual stress field in the as-welded condition [8].

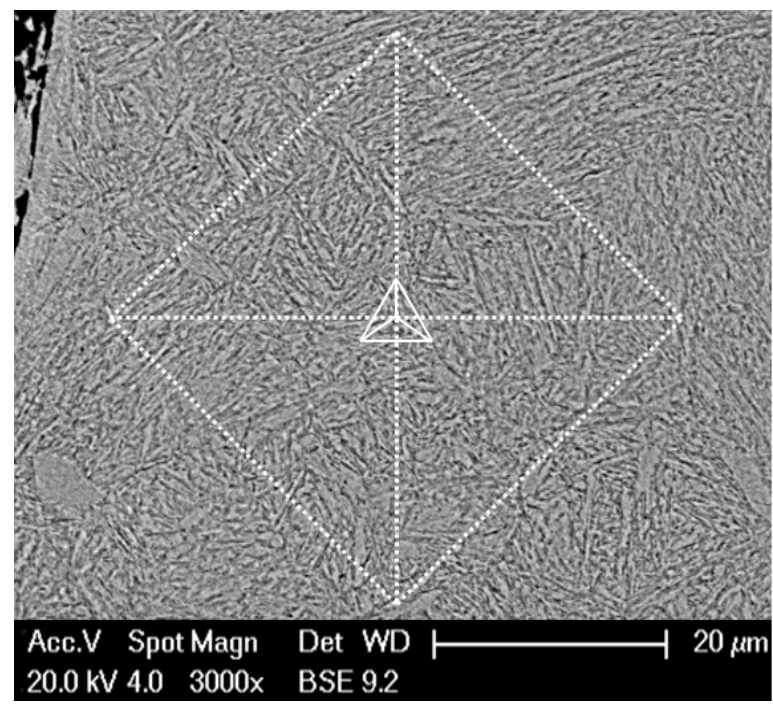

Figure 17. Schematic illustration of the impression left by a Vickers indenter loaded at $0.1 \mathrm{~kg}$ and the projected area of the Berkovich indenter penetrating the tempered martensite lattice.

Having validated the results of the inverse analysis with experimental data extracted from a CrMoV steel in the tempered condition, TM can be used as a reference to test the results obtained for the QM and OTM as follows. Martensite in the quenched and over-tempered condition exhibits a Vickers hardness of approximately 760HV0.1, and 375HV0.1 respectively, or 1.52 and 0.75 respectively the value of the tempered martensite located outside the HAZ (500HV0.1). These ratios are consistent with the optimized values of yield stress obtained by the proposed inverse analysis technique as summarized in Table 1, 2170 MPa for quenched martensite and $952 \mathrm{MPa}$ for over-tempered martensite, or 1.54 and 0.68 the optimized value of yield stress of the tempered martensite (1409 MPa) respectively. The comparison is valid given the relationship between Vickers hardness and yield stress derived by Tabor [30].The area of the impression left by the Vickers indenter loaded to $0.1 \mathrm{~kg}$ in the 
tempered martensite is approximately 52 times the projected area of the Berkovich indenter at full load $(0.2 \mathrm{~N})$ as schematically illustrated in Figure 17; therefore due to the significantly larger number of grains tested by the Vickers indenter compared to the volume covered by the Berkovich indenter, and the fact that the microhardness test neglects the participation of elastic strains, a slight variation in hardness value, and consequently in the value of yield stress is expected as it is the case in this study. These results justify the applicability of the proposed inverse analysis in the characterisation of material property variation across an IFW of $\mathrm{CrMoV}$ steel. The optimized parameters can be used therefore to model each of the material phases present during the IFW process in order to provide more accurate material data for use in FE models to improve the prediction of the residual stress field in the aswelded condition and to aid the assessment of the performance of the weld under in-service conditions.

\section{Conclusions}

This work describes an inverse analysis of the depth-sensing indentation technique applied in the extraction of elastic-plastic properties of a parent phase, tempered martensite, and two child phases, quenched martensite and over-tempered martensite, across the joint of two IFWed sections of CrMoV steel. The accuracy of the FE model implemented in this study to simulate the indentation process of $\mathrm{CrMoV}$ steel in the tempered condition has been validated against experimental data. The FE simulated $P-h$ curve of TM were in good agreement with the $P$ - $h$ curve recorded by the Nanotest NTX unit, however the FE simulation slightly overestimated in $\sim 1 \%$ the measured depth at full load $\left(h_{\max }\right)$ and $\sim 2.9 \%$ after the load has been completely removed $\left(h_{f}\right)$. The discrepancy can be attributed to the different constitutive behaviour of a small volume of material compared to the bulk metal properties, to the power 
law idealization of the constitutive relationship, and to the complexities of representing the mechanics of contact. A parametric analysis was carried out using this FE model in order to study the sensitivity of the $P$ - $h$ curve to the Young's modulus $(E)$, yield stress $\left(\sigma_{y}\right)$, Poisson's ratio $(v)$ and strain hardening exponent $(n)$; the results showed a high impact to the loading curvature and consequently the value of maximum depth $\left(h_{\max }\right)$ in up to $0.17: 1 \%$ and $0.34: 1 \%$ due to variations in $E$ and $\sigma_{y}$ respectively. Additionally, the parametric analysis provides evidence of the effect of the Young's modulus on the value of contact stiffness $(S)$ of the material during unloading, which controls the slope of the unloading section in a typical $P-h$ curve. Based on the unification of knowledge gained from experimental data of the alloy studied in this work, the experimental programme carried out and the results provided by the parametric analysis, it was possible to build an inverse analysis capable of generating a more accurate material database containing full elastic-plastic stress-strain relationships of up to three phases involved during the IFW process of a $\mathrm{CrMoV}$ steel, namely tempered martensite, quenched martensite and over-tempered martensite. The accuracy of the inverse analysis proposed in this study to predict the set of material properties that define the elasticplastic stress-strain relationship of each of these phases is supported and validated by its capability of fitting three experimental curves extracted from different locations across the joint, where these phases are known to exist, within a maximum relative difference of $1.5 \%$ in the values of maximum depth. Furthermore, based on the accepted relationship described by Tabor [30] between Vickers hardness $(H V)$ and yield stress $\left(\sigma_{y}\right)$, it was possible to validate the magnitudes of $\sigma_{y}$ provided by the optimization algorithm since the ratio of $\sigma_{y}$ between the tempered martensite (TM) and each child phase, quenched martensite (QM) and overtempered martensite (OTM), 1.54:1 and 0.68:1 respectively, is consistent with the ratio of $H V$ between each of these pairs, i.e. $1.52: 1$ and $0.75: 1$ respectively, as shown in the microhardness test conducted across the joint of an inertia friction weld (IFW) of two 
cylindrical sections of $\mathrm{CrMoV}$ steel. Furthermore, the model proved its reliability to converge to an optimum solution in terms of the optimized parameters $E$ and $\sigma_{y}$ to within less than 1.2 and $3.5 \%$ respectively, regardless of the position of the initial guess parameters. The relatively higher variation $(<15 \%)$ in the optimized value of $n$ can be attributed to the low sensitivity of the $P$ - $h$ curve to this parameter and therefore an improved model including information regarding the evolution of the surface profile of indentation, which is strongly linked to the plastic behaviour, is being prepared for a future publication.

\section{Acknowledgments}

The authors wish to thank Rolls-Royce plc, Aerospace Group, for their support of this research, which was carried out at the University Technology Centre in Gas Turbine Transmission Systems at the University of Nottingham. The views expressed in this paper are those of the authors and not necessarily those of Rolls-Royce plc, Aerospace Group.

\section{References}

1. Bennett, C.J., Inertia Friction Welding of High Strength Aerospace Alloys. 2007, The University of Nottingham: Nottingham.

2. $\quad$ Moat, R., Karadge, M., Preuss, M., Bray, S., Rawson, M., Phase transformations across high strength dissimilar steel inertia friction weld. Journal of Materials Processing Technology, 2008. 204(1-3): p. 48-58.

3. Moat, R., Karadge, M., Preuss, M., Bray, S., Rawson, M., Detailed Diffraction and Electron Microscopy Study of Inertia-Friction-Welded Dissimilar High-Strength Steels. Metallurgical and Materials Transactions A, 2011. 42(10): p. 3130-3140.

4. Mohammed, M.B., Process modelling of inertia friction welding process using finite element analysis. 2011, The University of Nottingham: Nottingham.

5. Messler, R.W., Joining of materials and structures : from pragmatic process to enabling technology. 1942, Boston ; Oxford Butterworth-Heinemann.

6. Bennett, C.J., Attallah, M.M., Preuss, M., Shipway, P.H., Hyde, T.H., and Bray, S., Finite Element Modeling of the Inertia Friction Welding of Dissimilar High-Strength Steels. Metallurgical and Materials Transactions A, 2013. 44(11): p. 5054-5064.

7. Moat, R.J., Hughes, D.J., Steuwer, A., Iqbal, N., Preuss, M., Bray, S.E., Rawson, M., Residual Stresses in Inertia-Friction-Welded Dissimilar High-Strength Steels. Metallurgical and Materials Transactions A, 2009. 40(9): p. 2098-2108.

8. Iracheta, O., Bennett, C.J., Sun, W., A sensitivity study of parameters affecting residual stress predictions in finit element modelling of the inertia friction welding process. International Journal of Solids and Structures, 2015. 71: p. 180-193.

9. Fischer-Cripps, A.C., Nanoindentation. Mechanical Engineering Series. 2004, New York: Springer 
10. Oliver, W.C., Pharr, G.M., An improved technique for determining hardness and elastic modulus using load and displacement sensing indentation experiments. Journal of Materials Research, 1992. 7(6): p. 1564-1583.

11. Sneddon, I.N., The relation between load and penetration in the axisymmetric Boussinesq problem for a punch of arbitrary profile. International Journal of Engineering Science, 1965. 3(1): p. 47-57.

12. Ternovskii, A.P., Alekhin, V.P., Shorshorov, M.K., Khrushchov, M.M., Skvortsov, V.N., Micromechanical testing of materials by depression. Zavodskaya Laboratoriya, 1974. 39(10): p. 12421247.

13. Tabor, D., A Simple Theory of Static and Dynamic Hardness. Proceedings of the Royal Society of London A, 1948. 192: p. 247-274.

14. Stillwell, N.A., Tabor, D., Elastic Recovery of Conical Indentations. Proceedings of the Physical Society, 1961. 78(2): p. 169-179.

15. Giannakopoulos, A.E., Larsson, P.-L., Vestergaard, R. , Analysis of Vickers indentation. International Journal of Solids and Structures, 1994. 31: p. 2679-2708.

16. Larsson, P.-L., Giannakopoulos, A. E., Söderlund E., Rowcliffe, D. J., Vestergaard, R., Analysis of berkovich indentation. International Journal of Solids and Structures, 1996. 33(2): p. 221-248.

17. Venkatesh, T.A., Van Vliet, K. J., Giannakopoulos, A. E., Suresh, S., Determination of elasto-plastic properties by instrumented sharp indentation: guidelines for property extraction. Scripta Materialia, 2000. 42: p. 833-839.

18. Giannakopoulos, A.E., Suresh, S., Determination of elastoplastic properties by instrumented sharp indentation. Scripta Materialia, 1999. 40(10): p. 1191-1198.

19. Cheng, Y., Cheng, C., Scaling approach to conical indentation in elastic-plastic solids with work hardening. Journal of Applied Physics, 1998. 84: p. 1284-1291.

20. Cheng, Y., Cheng, C., Relationships between hardness, elastic modulus, and the work of indentation. Applied Physics Letters, 1998. 73(5): p. 614-616.

21. Dao, M., Chollacoop, N., Van Vliet, K. J., Venkatesh, T. A., Suresh, S., Computational modeling of the forward and reverse problems in instrumented sharp indentation. Acta Materialia, 2001. 49: p. 38993918.

22. Kang, J.J., Becker, A. A., Sun W., A combined dimensional analysis and optimization approach for determining elastic-plastic properties from indentation test. Journal of Strain Analysis for Engineering Design, 2011. 46: p. 749-759.

23. Kang, J.J., Becker, A. A., Sun W., Determining elastic-plastic properties from indentation data obtained from finite element simulations and experimental results. International Journal of Mechanical Sciences, 2012. 62(1): p. 34-46.

24. Soh, H., Fretting wear studies of aeroengine materials. 2006, The University of Nottingham: Nottingham.

25. Liu, L., Ogasawara, N., Chiba, N., Chen, X., Can indentation technique measure unique elastoplastic properties? Journal of Materials Research, 2009. 24(03): p. 784-800.

26. Tho, K.K., Swaddiwudhipong, S., Liu, Z.S, Zeng, K., Hua, J., Uniqueness of reverse analysis from conical indentation tests. Journal of Materials Research, 2004. 19(08): p. 2498-2502.

27. Sakharova, N.A., Fernandes, J. V., Antunes, J. M., Oliveira, M. C., Comparison between Berkovich, Vickers and conical indentation tests: A three-dimensional numerical simulation study. International Journal of Solids and Structures, 2009. 46: p. 1095-1104.

28. Meyers, M.A., Mechanical behavior of materials. 2009, Cambridge: Cambridge University Press.

29. Committee, A.I.H., ASM Handbook, Volume 1, Properties and Selection: Irons, Steels, and High Performance Alloys. 2005, Materials Park, Ohio: ASM International.

30. Tabor, D., The hardness of metals. Oxford Classic Texts in the Physical Sciences. 1951, Oxford: Oxford University Press.

31. Bhadeshia, H., Honeycombe, R., Steels: Microstructure and properties. 2006, Oxford: ButterworthHeinemann,. 